Article

\title{
Aging and Resilience: Older Women's Responses to Change and Adversity
}

\section{Cari L. Gulbrandsen * and Christine Walsh}

Faculty of Social Work, University of Calgary, 2500 University Dr. NW, Calgary, AB T2N 1N4, Canada; E-Mail: cwalsh@uclagary.ca

* Author to whom correspondence should be addressed; E-Mail: cgulbran@ucalgary.ca; Tel.: +1-403-220-2274.

Academic Editor: Katrina McDonald

Received: 1 June 2015 / Accepted: 11 November 2015 / Published: 17 November 2015

\begin{abstract}
The primary objective of the qualitative study was to describe women's resilience in older adulthood according to older women's interpretations of their experiences and the contexts of their lives. Intersectionality and critical feminist gerontology served as theoretical frameworks for examining, interpreting and highlighted the dynamic nature of intersecting identities and the interrelationships between identity and contextual factors. Constructivist grounded theory methodology was used to identify themes that represent older women's subjective interpretations of their experiences with adversity and to construct definitions of resilience based on their experiences. The aspects of identity that women in the study associated with their experiences of adversity and their resilience were age, physical and mental health, marital status and income. Women in the study emphasized how subjective interpretations influenced the meaning they associated with events, circumstances, or changes that accompanied aging and their understanding of the role of identities in those experiences.
\end{abstract}

Keywords: aging; women; resilience; intersectionality

\section{Introduction}

Gerontology researchers have identified distinct gender differences related to aging and have associated these differences with adverse consequences and disadvantage for older women [1-3]. In addition to 
describing how gender shapes older women's experiences of aging, researchers have described how other identity factors influence women's experiences with aging. According to aging researchers, physical and mental health, mobility, income, and marital status are also significant identity factors that influence women's experiences of aging because of changes in health and circumstances that are likely to occur as women become older [1-6]. Studies that have examined the role of identity differences in women's aging have focused primarily on the detrimental nature of changes associated with women's aging [4-6]. Despite the inevitability of older women experiencing age related changes and adversity as they become older, the role of their resilience in reconciling age related changes and adversity has scarcely been explored [7,8]. By examining older women's resilience, this study aims to recognize older women's strengths and capacity to adapt or positively respond to change, challenges or adversity. This study follows the direction recommended by disability scholars, who have argued for approaches to studying resilience that identify individuals' subjectively constructed definitions of resilience and subjective interpretations of their experiences with adversity $[9,10]$. Accordingly, a priority that guided the study was to preserve the coherence, conviction and integrity of women's stories and to honor participants as the legitimate experts of their own resilience and as co-creators of new knowledge about older women's resilience.

\subsection{Defining Resilience}

Definitions articulated by scholars who have studied older women's resilience served as a departure point for constructing nuanced definitions of resilience to represent the unique experiences of the older women who participated in the study. According to Charmaz [11] constructivist grounded theory uses "sensitizing concepts" identified in literature to formulate tentative understandings of the phenomenon of interest. Charmaz [11] referred to sensitizing concepts for researchers as, "tentative tools for developing their ideas about processes that they define in their data" (p. 17). Consequently, this constructivist grounded theory investigation involved examining scholarly literature on older women's resilience to determine how researchers have approached studying older women's resilience and to identify factors that researchers have associated with the construct. Sensitizing concepts were derived from both quantitative and qualitative research on older women's resilience. It is important to note that it was not assumed that factors and themes identified by resilience researchers would be relevant to the experiences of women in the study. As Charmaz [11] recommends with respect to constructivist grounded theory investigations [11], our study was receptive to participants identifying novel aspects of resilience, unique definitions of resilience and personally meaningful factors that they implicate in their resilience and experiences with adversity.

Researchers who have studied older women's resilience have proposed conceptual definitions to articulate what they mean by, "resilience" and have also identified factors, constructs and themes related to older women's resilience $[7,10,12,13]$. Quantitative researchers have asserted that resilience is a multidimensional psychological construct and demonstrated that resilience can be measured. Quantitative researchers have defined older women's resilience according to its relationship with other constructs such as optimism, self-rated mental health, self-rated successful aging and spirituality and contextual factors, such social support. [13-15]. Of interest in the study was if the factors identified by 
quantitative researchers were perceived as significant by participants or meaningfully related to their resilience.

In contrast, qualitative researchers have proposed conceptual definitions of older women's resilience. In their seminal qualitative study of older women's resilience, Wagnild and Young [7] defined resilience as "emotional stamina" and indicated "resilience has been used to describe persons who display courage and adaptability in the wake of life's misfortunes" (p. 254). Wagnild and Young [7] defined older women's resilience according to a constellation of interrelated themes that represented the experiences of the older women who participated in their study. The themes they identified to describe older women's resilience were equanimity; self-reliance; existential aloneness; perseverance; and meaningfulness. In another qualitative study of older women's resilience, Felten and Hall [12] conceptualized the resilience of older women over age 85 as "the ability to achieve, retain and/or regain a level of physical and/or emotional health, after devastating illness or loss" (p. 2). The definitions proposed by qualitative researchers and the themes they have associated with older women's resilience also served as sensitizing concepts in this study.

This study was also informed by scholars' critiques of definitions of resilience and approaches to studying resilience $[9,10]$. Specifically, this study follows the direction of disability scholars, who have challenged assumptions about what constitutes resilience and who has legitimate authority to determine if an individual is resilient. Disability studies scholars' critiques are relevant to investigations of older women's resilience, as changes or decline in health, mobility and physical functioning frequently occur in parallel with aging $[9,10]$.

The fundamental critique of existing conceptual definitions of resilience proposed by disability studies scholars is the how most definitions use normative standards of health and functional status as a basis for judging individuals' resilience [9,10]. Consequently, individuals whose lives don't conform to normative standards of health and functional status $[9,10]$ are assumed to be deficient in or incapable of resilience. Disability studies scholars have noted that most definitions of resilience value independence and autonomy and evaluate individuals' resilience according to these values $[9,10]$. Hutcheon and Wolbring [10] advocated for constructivist approaches to defining resilience whereby individuals constructing their own meanings of resilience, which "provides space for multiple and subjective understandings of resilience, for a non-hierarchical relationship between risk and protective factors, and for individual, cultural and social differences in understandings of resilience” (p. 247). In response to disability scholars' assertion that some identities are privileged and others are marginalized in conceptualizations and representations of resilience, this study attuned to participants' criteria for determining their own resilience in the context of their lives.

Researchers who have studied older women's resilience have also focused critiques on the limited identities represented in study samples and have recommended that future research on older women's resilience examine how resilience varies according to identity differences such as gender, age, ethnicity, health, income, and geographic location [16-19] Although disability scholars focused on health and mobility, we considered the role of multiple other identity factors and how they contributed to women's experiences with adversity and resilience. 


\subsection{Women's Aging and Identity Factors}

The role of identity differences is increasingly recognized in contributing to the complexity of women's experiences of aging [16-27]. Researchers who have described how women experience aging differently than men contribute a rationale for examining older women's resilience and identify aspects of identity that shape older women's experiences with aging and adversity. Older women's longevity contributes to an increased likelihood of experiencing health problems and a result, older women are more likely to suffer from stroke and hypertension, have functional limitations, report lower self-rated health [18,19] and more chronic health conditions [2] than their male counterparts. With respect to psychological health, older women are more likely to be diagnosed with anxiety, depression and post-traumatic stress disorder and more likely to take psychotropic medications than men [20].

There are also distinct psychosocial and demographic gender differences in aging. As an example, older women are more likely to be widowed and less likely to remarry after being widowed than older men [6,21] Scholars have also described limited income and financial resources constrains older women's lives and how gender inequality in the workforce, time away from the workforce and fulfilling caregiving roles result in women having limited or insufficient income to sustain basic needs in older adulthood [6,21]. Gillen and Kim [21] reported that single older women and widows have much lower incomes in old age than married older women and men and that widowhood drastically reduces older women's earnings, pensions and assets. In reference to her study on formerly homeless older women, Waldbrook [22] contended that fluctuating income throughout women's lives directly impacts the quality of their housing and their access to basic needs resources when they are older. She underscored how women's income intersects with age, mental and physical health, ethnicity, education, and marital status.

Several studies have suggested that marital status is a significant identity factor with significant social and economic consequences for older women. Utz, Caserta, and Lund [23] noted that widowhood is associated with declines in women's physical and mental health. However, other researchers have emphasized older women's positive adjustment and resilience in responding to the loss of a spouse [24,25]. As an example, in a qualitative study with British widows, Collins [25] portrayed older women's experience of losing a spouse as a transition that prompted changes in identity and attributed older women's resilience to contextual factors, such as social support and personal agency; engaging skills they learned earlier in their lives, such as self-sufficiency.

Scholars have reported the effects of declining health and illness on women's experiences of aging and suggested that chronic illness for older women involves physical, psychological, social and economic loss [2,17]. Lyyra and Heikkinen's [17] found that older women diagnosed with rheumatoid arthritis rated their health according to their ability to complete daily activities, to engage in social participation and relationships, the extent to which they were inconvenienced by disability, their mental health, their independence and their autonomy.

Gerontology researchers have elaborated on the role of specific identity factors in women's aging. However, the majority of studies focus on specific identity factors. Fewer studies have explored the interaction among identity factors or the role of change or adversity on older women's intersecting identities. 


\subsection{Theoretical Frameworks for Examining Older Women's Resilience}

Intersectionality theory and critical feminist gerontology are suitable frameworks for examining older women's dynamic, intersecting identities [24,25]. Intersectionality theory and critical feminist gerontology have been proposed as complementary approaches to studying women's aging because both theoretical orientations focus on the intersection of diverse identities influences women's experiences with aging [24,25], Intersectionality theory, introduced by Crenshaw [26] as "a way of mediating the tension between assertions of multiple identity and the ongoing necessity of group politics" (p. 18), has its roots in theorizing women of colour [25,26]. Crenshaw [26] cultivated consciousness of the numerous intersections at which oppression can be located, thus encouraging an appreciation of the complexity of difference and its influence on identity and experience. By focusing on the complex interrelationships among identity factors, intersectionality theory promotes understanding the complexity of older women's aging. Moore [27] recognized age as a shifting identity marker, unlike other aspects of identity such as race and argued that with respect to ageism, intersectionality theory must be viewed within a broader context that considers the role of structural factors and other aspects of difference besides age in inequality and oppression. Further, Calasanti [28] acknowledged that although ageism qualifies as oppression in its own right, it is inextricably linked to systems of multiple, interlocking oppressions that cannot be separated in to discrete categories.

According to Wilinska [3], dimensions of difference within an intersectionality framework are intended to be integrative rather than additive, with no single aspect of difference considered a priority; intersectionality theory proposes that multiple aspects of difference intersect to shape experience. Krekula [29] referred to the "double jeopardy" effect, whereby the integrative effect of multiple dimensions of oppression is thought to have more detrimental consequences than one single aspect of difference and commented on how the double jeopardy effect of ageism and sexism at a structural level can make the experience of aging more problematic for women.

Similarly, from the perspective of critical feminist gerontology, Frexias, Luque and Reina [30] explained how multiple, intersecting identity factors influence women's experiences of aging:

Critical gerontology analyzes the extent to which political and socioeconomic factors interact to shape the experience of aging with regards gender, ethnic background, and social class as variables on which the life course of individuals pivot, insofar as it predetermines their position in the social order. (p. 44)

Critical feminist gerontology scholars have challenged the marginalization of older women within feminist literature and discourses of aging that reinforce negative assumptions about older women [30-33] and have asserted that women's experiences of aging need to be made more visible [26]. Similarly, Fine [31] noted that critical feminist gerontology contributes to feminist scholarship by accounting for the complexity of older women's lives and histories. Although it is important to recognize adversities that older women encounter, critical feminist gerontologists caution that focusing exclusively on women's aging as catastrophic or adverse reinforces stereotypes of older women as fragile and vulnerable [30].

By focusing on older women's resilience, this study aims to recognize women's capacity to cope with, adapt to or respond positively to change and adversity and to contribute understanding of the 
highly individual nature of older women's resilience, how women construct meaning from their experiences and how other identity differences intersect with age and gender to shape older women's adversity and resilience. By defining resilience from older women's perspectives in the context of age related changes and according to their multiple, fluid identities, older women's resilience can be more deeply understood.

\section{Methods}

The purpose of the study was to consult directly with older women about their subjective experiences and understanding of their resilience and experiences with age related adversity. Study participants were women or individuals who identify as women who were 55 years of age and over at the time of the interview. Age 55 and over was chosen to include women who are transitioning between middle age and older adulthood. Before the study commenced, ethics approval was obtained from the University Research Ethics Board. Women were invited to participate in the study via an electronic recruitment advertisement, which were circulated to members of local women's organizations and the provincial social work professional association.

\section{Participants}

Twenty-two women ranging in age between 55 and 73 consented to participate in the study and provided written informed consent. Table 1 outlines basic demographic information about the women who participated in the study.

Table 1. Demographic Characteristics of Participants.

\begin{tabular}{ccc}
\hline Name/Pseudonym & Age & Ethnicity (Country of Origin) \\
\hline Susan & 67 & Canadian \\
Liz & 69 & Canadian \\
Irene & 73 & Canadian \\
Donna & 70 & Canadian \\
Roger & 73 & Canadian \\
Mary & 61 & Canadian \\
Aziza & 68 & African immigrant with Canadian citizenship \\
Siobhan & 55 & Canadian \\
Avril & 66 & British/immigrant withCanadian citizenship \\
Barbara & 65 & Caucasian \\
Amelia & 65 & Peruvian immigrant with Canadian citizenship \\
Lilija & 58 & Canadian \\
Athena & 64 & Canadian \\
Jean & 62 & Canadian \\
Carole & 59 & Canadian \\
Barbara & 65 & Canadian \\
Lib & 62 & Canadian \\
Paulina & 59 & Canadian \\
Georgia & 63 & Canadian \\
Lise & 57 & Canadian \\
Audrey & 58 & Canadian \\
Lyn & 61 & Canadian \\
\hline & &
\end{tabular}


The lead researcher conducted individual face-to-face individual interviews, lasting approximately 1-1.5 h, at a convenient time and location for the participants. At the beginning of the interview, participants provided information about age and ethnicity and whether they had enough income to afford to meet their basic needs. All of the women reported that they had enough money to meet their basic needs. Three of the women reported that they were concerned about their future financial stability. Seven of the women reported that they had been diagnosed with serious or chronic physical or mental health conditions in the last 5 years, including cancer, osteoarthritis, depression and ALS. Interviews were conducted with a field guide, consisting of open-ended questions about participants' experiences with and reflections on aging, adversity and resilience. Participants were also asked to articulate their own definitions of resilience. This paper examines women's accounts of their experiences with resilience in the context of change and adversity.

The computerized data analysis software program NVivo was used to manage the qualitative interview data. Data analysis proceeded according to constructivist grounded theory methodology as described by Charmaz [11]. Initially, the data was analyzed line by line to identifying text-based codes. Distinct units of meaning were then assigned with conceptual labels, with attached theoretical memos to capture researchers' reflexivity during the coding process. The constructivist grounded theory coding process involved two main phases; initial coding; the coding of words, lines, or segments of data, followed by focused coding, which involves categorizing the codes identified in the initial phase [11]. An overarching theme and related sub-themes were identified after analyzing all interview transcripts.

\section{Results}

Participants in the study constructed individual, contextualized and subjective meanings of resilience in the context of their age related changes. Women's resilience was evident in varying responses, depending on the nature of the change women encountered and its subjective meaning in the context of their lives. Thus, responding to change and adversity was identified as the overarching theme. Within this theme, the following four sub-themes were identified: (a) acceptance of the changes and consequences that accompany aging; (b) adjustment to adverse temporary or permanent changes; (c) recovery from setbacks, adverse events or changes in circumstances; and (d) personal growth resulting from change, circumstances or adversity. Whether or not specific changes, circumstances or events were viewed as adverse depended on participants' unique perspectives. Participants also identified and described mediating factors that influenced how they responded to change. They further outlined how their resilience was influenced by a complex interaction of individual factors including: hope, optimism, spirituality, self-sufficiency, maturity, learning, experience and self-understanding and contextual factors; social support from family and friends and support and resources from health and social services. Each of these sub-themes are described below and substantiated with illustrative quotes drawn from interview transcripts. Quotes are associated with women's first names or pseudonyms as women indicated on the consent forms.

\subsection{Acceptance of Changes}

Women in the study explained how they accept specific changes as inevitable aspects of aging. Women's reflections on inevitable changes related to advancing age illuminate how women construct 
subjective understandings of what changes mean in the context of their lives. Women in the study described how they reconciled their own meaning of advancing age with meanings others and society ascribe to their aging.

Participants emphasized the importance of accepting their transitions to becoming older women: accepting that they are older, and accepting the physical changes that accompany aging. Liz, age 68 emphasized the importance of accepting one's age:

For me personally, I think that it is really important to accept where you are in your life and live accordingly. You can't be 45 when you are 65. You can work out if that is what you enjoy doing, and staying healthy. I think that is important to do the best you can. It is so important to accept the age you are, especially when you are a senior. You may wish you are 45 but you are not. Why pretend? I knew one gal who had her hair a very dark brown and I hadn't seen her in probably about three months. In that length of time she had let it go and grow out and it is kind of silvery grey color. She looks so much better in my eyes. When I go by all the kiosks where they are selling all these creams and stuff to make you look younger I say, “Look, I am 68 years old, what can you do for me?” I mean if you are 40 and you want to keep your skin looking good, then fine. I really believe that so much of it is genetic. If your mom had a wrinkled face, you are probably going to have one. Part of it is if you are a smoker. Once you have the wrinkles, you have them and what are you going to do?

Jean, a 64-year old woman referred to societal pressure to resist aging. She expressed that for her, acceptance of aging involves sharing with others that she embraces aging.

All you ever hear is how you don't want to get old, you don't want to look old, and you don't want to act old. There seems to be a fear about aging and looking old and getting old. I think it is actually something to look forward to. Just everything in the media seems to suggest to people that you don't want to get old and you don't want to get old. There is almost a fear of getting old. If you say you are old, people say, "Oh, no, no, no, you are not old". I feel like saying, "As a matter of fact, I am, and I like it."

Susan, a 67-year old participant, noticed how her advancing age influences how she is treated in the workplace. Her response to adverse reactions to her age is to accept ageism as an inevitable form of discrimination towards her, as an older woman.

I have noticed that pretty, young people get more attention and more support and more requests are fulfilled with less resistance. Yeah, I have noticed that. I am used to it. I thought about it and, while it is noticeable, I don't dwell on it. I have realized that that too is part of our social structure at this point. I look forward to us being able to overcome those things, but it is where we are at socially.

\subsection{Adjusting to Change and Adversity}

Women in the study described how they accommodated change by adjusting to new realizations, circumstances, challenges and constraints introduced by advancing age and adverse changes in health. 
Women responded by adjusting their lifestyles, activities and expectations when faced with chronic conditions or permanent changes.

Mary, age 61, described how approaching her 60th birthday triggered a mental health crisis for her. She reflected on her negative reaction to this birthday and how her awareness of her age triggered a traumatic adjustment in her expectations and in her perception of herself.

It was absolutely wonderful until I started to get closer to my 60th birthday. So, my life experiences as far as aging and getting older had been, "It is natural and everything is okay, and everything is going fine". As I started to get closer to 60, I am not really sure what happened. It wasn't a diagnosed depression, but I really struggled with a lot of the changes that were physically going on in my body and my thought process as far as how I was seeing myself as an older person. I was recognizing I couldn't do all the things I used to do. I don't have the energy that I used to have. It has probably been a slow process, but it feels like I just jumped up one day and my calendar turned to 60. It was like somebody took a baseball bat and took my knees out. It was a very difficult time period for me. I kept on thinking I could do all the things that I had done, but I can't. I didn't give a lot of consideration to it, but turning 60 really, it was like a big hallmark for me.

Participants identified and elaborated on individual and contextual factors that facilitate their adjustment to adverse temporary or permanent changes that arise as they age. Several participants reflected on changes in mental and physical health and explained how these changes prompted significant adjustments. Carole, age 60 described how she adjusted to being diagnosed with Amyotrophic Lateral Sclerosis (ALS) and found innovative ways to continue activities she valued. She reflected on the pride she takes in contributing to the community as a social worker. After her diagnoses and as her symptoms of ALS progressed, she found a way to continue her counseling practice.

I tap into a routine. That helps. My routine involves exercise, massage, therapy, and volunteering with the ALS society. I do some online counseling. I stay connected to your profession. I find if I can interact with others I feel less stressed. Clients are dealing with the same kind of stress. I work with people with ALS. They have limited mobility and speech issues. Clients express themselves through a chat interface. Online counseling makes it possible for clients to communicate and receive peer support.

Aziza, 68, explained how living with a worsening chronic health condition was source of adversity she had to cope with as osteoarthritis increasingly limited her activities. She described how she responded to her chronic health condition by developing coping strategies for managing physical pain.

It's difficult when you have osteoarthritis that is quite advanced. I have had several spinal reconstruction surgeries. So, it kind of holds you back sometimes. It is an every day thing, the arthritis. It is with you seven days a week. It gets worse, but it doesn't get less. That is the only thing that is a stumbling block for me, especially today when it is raining. It makes my arthritis worse and I have to take an extra pain killer. I only take the strong painkillers when I am going out to do something. When I am staying in, I take my over-the counter pain medication. Honestly, I save painkiller for special days when I am going to my seniors group, and I am going to do volunteer work and I will need that extra kick; definitely, because it stays in your system longer. The only way I can enjoy what I am doing is to be pain free for that time. You know what, life is tough and you have to make tough choices. 
I don't mind, honestly, I don't mind. But I wish we had a bit more backing from the government.

She further elaborated on how living with a limited income restricted the extent of treatment she could afford to treat a chronic condition and recognized the adjustments she had to make in her treatment plan because of her income.

I am paying for chiropractic but I have to limit the treatments I go for, but it does help. I do go because I would rather go and then cut down on one strong painkiller. I have insurance coverage and they will only cover $70 \%$.

In contrast, Lise, 57 acknowledged that having financial security influences how she envisions her future as she ages and adjusts to retirement.

I think I am very fortunate compared to other women. I know I have a government pension. I do know that I will have adequate income. I know a lot of women who say, "I'll have to work until I am 65 or until whenever and I don't have that financial security." I think financial security is a big piece.

\subsection{Recovering from Adversity and Change}

Women in the study reflected on how they restored their mental or physical health or well-being after experiencing adverse changes in health and how they recovered from significant setbacks and adverse events. For example, Georgia, age 63, was hospitalized in the recent past for several months due to a severe mental health diagnoses. She reflected on how social support from health care staff helped her recover from the change to her mental health and the long period of hospitalization.

There were some very caring people. They made a difference. You could tell that they were real people. You could tell they weren't behind a mask. Some people were genuine but some people were behind their mask, like 'I'm a professional and you're a poor client or something or other". You really, really sensed that. There were a few that would help just by being human. I didn't need any physical care. Some staff would spend time playing cards with me and would go out for a walk with me, which was above and beyond their normal duties. Some of the staff would talk or give you a hug, personal kinds of things.

Fifty-eight year old Lilija explained how social support provided comforted and helped her to recover from a traumatic divorce experience:

My own personal philosophy is that life takes teamwork, to share sorrow, to share joy and to do that with compassion. That to me says it all in my own personal life. It all boils down to that for me. Yes, friends and family. When I went through a difficult time with my second marriage, I knew the biggest hurt when the family broke up would be to see my children go through it and to suffer. I knew that would be very hurtful. Then moving ahead, it took friends and family and drawing on many people. It took a lot, mentally and emotionally. There were times when I wasn't strong and was afraid. I just needed ten minutes with someone on the phone. It was those little connections. 
Lib, age 62, explained how obtaining support from a health professional after a mental health diagnosis aided her physical and mental recovery.

Basically, I was diagnosed with adjustment disorder, with high anxiety, some depression and most likely post-traumatic stress disorder because of the highly crisis oriented work that I had done for all of those years. So, I slowly put myself together with the help of my family doctor and a clinical or behavioural social worker. I think it was around Christmas time of that year when I finally had a good sleep, and I have been doing better ever since.

Mary also explained how social support contributed to recovering the difficult time that coincided with 60th birthday.

I have a lot of lady friends. We belong to a running-walking group. Our age range is about 62 all the way down to 39. What got me through was just camaraderie with other women who were all at different stages. Some were working, some were not working, some were grandparents and some weren't yet. What got me through were connections in my social world and in my workplace as well.

\subsection{Personal Growth in Response to Change and Adversity}

Women in the study described how their response to adversity stimulated positive personal growth or improved quality of life. Paulina, age 59, cited spirituality as essential in supporting her recovery from depression and in maintaining her sobriety:

I would drink at night to go to bed. I was working two jobs for a while. I would be working seven days a week and I would go home to drink a few beers, which turned out to be six beers. I eventually became depressed because of the drinking and then I hated myself the next day. It was the thoughts that were going through my head that I hated. I would have these crazy thoughts. My supervisor suggested I take a couple of weeks off work. To me, that was my rock bottom. I went to the wellness department. They referred me to a psychologist and he suggested I might have a drinking problem. I didn't think I did. I knew I drank a lot but I didn't think I had a willpower issue. I started going to Alcoholics Anonymous (AA) meetings, and the moment I walked in, I felt at home. Part of being sober was turning your life over to a higher power. I started seeing God working. Then I started going to church.

Participants elaborated on how their perspectives or self-awareness or self-understanding transformed as they surmounted challenges or obstacles. Siobhan, age 55, commented on how transitioning from younger to older adulthood stimulated growth in her self-awareness and assertiveness:

I think I have grown as a human being, as I have aged, I think through some of the struggles in my life. I remember hitting my forties and then hitting my fifties and thinking, "This is good!" I think I have finally figure out who I am and my place. As a younger women I really struggled to find my own voice, I guess and my own power. I really identified with how I looked and I felt that I had to work very, very hard to prove myself or to prove that I was smart and capable. I think I very much was always someone else's opinion came before my own. I didn’t really find my own voice, until I had some life experience. 
Similarly, Lib's experience with cancer diagnosis and treatment prompted a transformation in her perspective of her own health. Although she recognized her illness experience as adversity, recovering from it presented an opportunity to approach her life and her perspective on her health differently than she did before her diagnosis.

I thought I knew what a "new normal" was after I went through treatment but, it is just recently that I am beginning to understand what that new normal is. It is basically making decisions or re-evaluating things with a new bar or a new standard in place. It is not like it changed me, but it basically made me look at valuing myself and my time and honoring my body in an enhanced way. It is not different, but it is brighter and more vital.

Lilija, age 58, described the difficult transition she experienced following a painful divorce and predicted that the resilience she developed in that situation would help her cope with adversity as she becomes older:

I got a very small, little old, old home tucked in the woods and that is where I lived. It was one of the hardest years of my life, but one of the very best. I felt like there was this threshold that I crossed where I started to look at myself and what I was running from and my fears. It was horribly hard but coming from that transition, but I felt so much stronger and had a better skill set and confidence in myself. So, I know that there will be hard things with aging and there's going to be lots coming. I might lose people I love. Or, I might become ill and have to face that my life is coming to an end sooner than I want.

\section{Conclusions}

Scholars have advocated for conceptualizations of resilience that are based on older adults' definitions and subjective experiences. According to Wild, Wiles and Allen [34], "older people's definitions tend to be more multidimensional, nuanced, contextualized, and attentive to balance and tension than the rather more narrowly focused normative definitions often used by researchers (p. 17). Women in the study constructed new knowledge about older women's resilience by reflecting on how they have accepted, adapted to, recovered from or transcended change and adversity. The women in the study defined resilience according to the subjective understandings they construct about their responses to change and adversity as they age.

Based on the individual accounts of the women in the study, the researchers formulated an encompassing, multidimensional definition of older women's resilience: (a) Resilience is an awareness and subjective understanding of how one accepts, adjusts to, recovers from or transcends change or adversity; (b) Resilience involves interpreting the significance of identities in one's experiences of change or adversity; and (c) Resilience involves the mobilization of internal and external resources to respond to change or adversity. Participants described how they focused their attention on coping with change and adversity and on mobilizing internal and external resources while they were in the midst of experiencing the change or adversity. Subsequent reflection on their responses to change was a catalyst for gleaning meaning from those experiences. The recollections that the women in the study shared suggests that their awareness of their resilience evolves gradually and becomes more deeply understood as they reflect on the meaning of the change and adversity in the context of their lives. This study captured 
examples that depict how women cultivate understanding of resilience by reflecting on their experiences with change and adversity.

Intersectionality theory as described by Crenshaw [26] usefully framed the experiences of women in the study according to changes in age, physical health, mental health, marital status, and income. Women described their interpretations of the significance of these identities in their experiences of aging and in doing so, illuminated the complexity of intersecting identity differences in the context of aging. It is important to note that women did not necessarily perceive changes to age, health, marital status and income as adverse. Women in the study also alluded to the dynamic nature of their interpretations and illuminated how their perceptions of circumstances or events were subject to change over time. An event or circumstance that was perceived as adversity initially was often construed differently when women reflected on the experience at a later date. Between the adverse events or circumstances and women's later recognition of their resilience women experienced periods of adjustment, understanding, and acceptance.

The quotes represent the diverse ways women in the study have interpreted and responded to their experiences with change and emphasize that changes and experiences are determined to be adverse only if individuals attached that meaning to them.

The findings from this study address the paucity of literature that examines older women's interpretations of change in older adulthood, their adaption to change or their recovery from change. Robertson [35] referred to significant changes experienced by adults in older life as transitions, and identified several transitions older adults commonly experience; retirement, health, becoming a caregiver, requiring care, and bereavement. Women in the study described the changes they experienced as they aged, how they interpreted changes in the context of their lives and how they responded to the changes.

Women in the study capitalized on their internal resources in the face of adversity and change. They also acknowledged that external support or intervention from their families, friends or health professionals bolstered their resilience when they encountered adversity. It was evident that some types of change, particularly significant changes in mental or physical health prompted women to secure social support and external resources they needed from their social networks and health and social service providers. Similarly, women's social networks provided emotional support when their marriages or relationships ended or when their spouses died. In contrast, the women in the study who described adverse circumstances due to limited income described making personal compromises by learning to live more frugally, even if it meant enduring pain or discomfort.

Participants described how relationships and support from friends, family, community members, counselors and at times strangers were instrumental in helping them cope with specific types of adversity. Several women reported that they were able to rely on friendships and relationships they had cultivated before adverse events occurred or close family members. Many of the women in the study described how they cultivated supportive relationships in the context of informal social networks cultivated through work, learning endeavors, athletic and recreational activities, volunteerism and membership in organizations. Women explained how many of the supportive relationships they relied were cultivated earlier in the lives and endured over time. Only two of the women described how social support from health care or social service workers contributed to their resilience in the context of adversity. 
Participants' descriptions of obtaining support and resources are consistent with findings reported by researchers who have examined older adults' coping and adaption strategies and their responses to adversity [36,37]. Gerontology researchers have described how older adults' resilience is strengthened by social support and suggested that social support also contributes to older adults' perceptions of their own mental and physical health [36]. However, researchers have also noted that chronic health conditions and declining health make it difficult for older adults to participate in social relationships and social activities [2,17] Wong, Wu, Gregorich, and Perez-Stable [37] identified sub-types of social support including tangible support, emotional support and companionship, financial support, and informational support and reported that the women in their study ranked emotional support as the most important as it related to self-reported physical and mental health. The older adults in the study conducted by Hildon et al. [36] also reinforced how supportive relationships buffered the effects of age related adversity.

Wong et al. [37] suggested that the importance older women ascribe to social support has significant implications for health social services provision for older women. Service providers who interact with older women can address gaps in social support for older women who lack a social support network so that isolated older women can cultivate external resources to draw upon when they experience adversity. By offering social support or connecting older women to sources of social support, service providers can strengthen older women's resilience and in the process, foster their mental and physical health.

It is important to note that women who identified limited income as a source of adversity described how they coped with their limited income by making compromises or by living frugally. Social support was not cited as a resource women turned to for support when they encountered difficult financial circumstances. In contrast, several participants recognized that having sufficient income contributed to their resilience and capacity to cope with adversity. Although all participants indicated they had enough income to meet their basic needs, the references to financial security made by women in the study alluded to the significance of having adequate financial resources.

Focusing on and supporting older women's resilience is complementary to strengths approaches to practice as strengths based approaches focus on building on specific strengths older women recognize, value and associate with their resilience. Browne et al. [38] proposed that strengths perspectives closely align with resiliency theory, "In contrast to a focus on adversities, deficits and pathologies so common in gerontology scholarship, resiliency theory draws from the strengths perspective, a philosophical standpoint that recognizes the inherent power and resilience of individuals and communities" (p. 255). Marttila, Johansson, Whitehead, and Burstrom [39] envisioned roles for human services professionals in fostering and supporting social services clients' resilience as finding individualized solutions to structural issues. The women in the study affirmed that they are the legitimate experts in their own experience and therefore, are in the best position to determine which resources will most effectively support their resilience. Chapin and Cox [40] suggested that social services for older adults are frequently guided by stereotypical views of older adults as dependent, frail and needing protection. Closely examining older women's subjective experiences and recognizing their strengths and resilience constitutes a meaningful step towards addressing pervasive, ageist stereotypes of older adults as helpless and fragile [30]. 
The women in the study illuminated the complex interaction of a limited number of identities; age, gender, physical health, mental health, marital status and income. The authors acknowledge that examining the role and relationships among identity differences in this study is limited by the identities represented by the women who participated in the study. Although the sample was relatively homogenous according to age, gender and ethnicity, participants' marital status, health and income varied. Women were not asked to disclose their sexual orientation or religion and the questions in the field guides did not ask participants to disclose information about these aspects of identity. Additional information related to identity factors was provided voluntarily in the course of the interviews. Therefore, it is possible that women did not fully disclose or reflect on all of their identities. Another limitation is that the oldest participant was 73 years of age, which means that the oldest cohort of women, were not represented in the sample.

The findings of the qualitative study contribute to a growing body research on older adults' and older women's resilience. Most of the researchers who have studied older women's resilience have focused on conceptually defining the construct, measuring it and describing the relationship between older women's resilience and related constructs; self-esteem, sense of coherence and self-rated mental health [13-15]. Participants in this study highlighted the importance of understanding women's subjective experiences with resilience in the context of their lives, according to how they attribute meaning to their experiences, how they conceive of changes, events and circumstances to be adverse and how they understand their own resilience. Examining older women's resilience as a complex, dynamic process that develops in the context of individual women's lives and according to multiple shifting identities is an compelling alternative to measuring older women's resilience according to pre-determined criteria, obtaining a snapshot of their resilience at a fixed point in time or using a score on a measure to judge if they are or are not resilient. By examining older women's resilience in the context of their lives, it is possible to appreciate the role of change in older women's resilience and to consider how meanings women attribute to change, adversity and resilience, change as they age.

\section{Acknowledgments}

The authors wish to gratefully acknowledge the contribution of the women who shared their time and contributed their reflections on aging, adversity and resilience to the study.

\section{Author Contributions}

Cari L. Gulbrandsen designed the study and completed the interviews, the preliminary interpretation of the data and draft of the manuscript. Christine A. Walsh contributed to the study design, data interpretation and development of the manuscript. Both authors have read and approved the final manuscript. 


\section{Conflicts of Interest}

The authors declare no conflict of interest.

\section{References}

1. Cornwell, B. Independence through social networks: Bridging potential among older women and men. J. Gerontol. Ser. B Pscyhol. Sci. Soc. Sci. 2011, 66, 782-794.

2. Clarke, L.H.; Bennett, E.V. Constructing the moral body: Self-care among older adults with multiple chronic conditions. Health 2013, 17, 211-228.

3. Wilińska, M. Because women will always be women and men are just getting older: Intersecting discourses of ageing and gender. Curr. Sociol. 2010, 58, 879-896.

4. Field-Springer, K. Red, hot, healthy mommas (Un) conventional understandings of women, health, and aging. Res. Aging 2012, 34, 692-713.

5. Hinze, S.W.; Lin, J.; Andersson, T.E. Can we capture the intersections? Older Black women, education, and health. Women's Health Issues 2012, 22, 91-98.

6. Martin-Matthews, A. Revisting widowhood in later life: Changes in patterns and profiles, advanced research and understanding. Can. J. Aging 2011, 30, 339-354.

7. Wagnild, G.; Young, H.M. Resilience among older women. J. Nurs. Scholarsh. 1990, 22, 252-255.

8. Damasio, B.F.; Borsa, J.C.; da Silva, J.P. 14-item Resilience Scale (RS-14): Psychometric properties of the Brazilian version. J. Nurs. Meas. 2011, 19, 131-145.

9. Hutcheon, E.; Wolbring, G. Deconstructing the resilience concept using an ableism lens: Implications for people with diverse abilities. Dilemata 2013, 11, 235-252.

10. Hutcheon, E.; Lashewicz, B. Theorizing resilience: Critiquing and unbounding a marginalizing concept. Disabil. Soc. 2014, 29, 1383-1397.

11. Charmaz, K. Constructing Grounded Theory: A Practical Guide Through Qualitative Analysis; Sage Publications: Thousand Oaks, CA, USA, 2006; pp. 16-17.

12. Felten, B.S.; Hall, J.M. Conceptualizing resilience in women older than 85: Overcoming adversity from illness or loss. J. Gerontol. Nurs. 2001, 27, 46-53.

13. Connor, K.M.; Davidson, J.R. Development of a new resilience scale: The Connor-Davidson resilience scale (CD-RISC). Depress. Anxiety 2003, 18, 76-82.

14. Lamond, A.J.; Depp, C.A.; Allison, M.; Langer, R.; Reichstadt, J.; Moore, D.J.; Golshan, S.; Ganiats, T.G.; Jeste, D.V. Measurement and predictors of resilience among community-dwelling older women. J. Psychiatr. Res. 2008, 43, 148-154.

15. Nygren, B.; Aléx, L.; Jonsén, E.; Gustafson, Y.; Norberg, A.; Lundman, B. Resilience, sense of coherence, purpose in life and self-transcendence in relation to perceived physical and mental health among the oldest old. Aging Ment. Health 2005, 9, 354-362.

16. Ailshire, A.; Beltran-Sanchez, H.; Crimmins, E. Social characteristics and health status of exceptionally long-lived Americans in the Health and Retirement Study. J. Am. Gerontol. Soc. 2011, 59, 2241-2248.

17. Lyyra, T.M.; Heikkinen, R.L. Perceived social support and mortality in older people. J. Gerontol. Ser. B Psychol. Sci. Soc. Sci. 2006, 61, 147-152. 
18. Hamid, T.A.; Momtaz, Y.A.; Abdul Rashid, S. Older women and lower self-rated health. Educ. Gerontol. 2010, 36, 521-528.

19. Iecovich, E.; Cwikel, J. The relationship between well-being and self-rated health among middle-aged and older women in Israel. Clin. Gerontol. 2010, 33, 255-269.

20. Malatesta, V. Introduction: The need to address older women's mental health issues. J. Women Aging 2007, 19, 1-12.

21. Gillen, M.; Kim, H. Older women and poverty transition: Consequences of income source changes from widowhood. J. Appl. Gerontol. 2009, 28, 320-341.

22. Waldbrook, N. Formerly homeless, older women's experiences with health, housing, and aging. J. Women Aging 2013, 25, 337-357.

23. Utz, R.L.; Caserta, M.; Lund, D. Grief, depressive symptoms, and physical health among recently bereaved spouses. Gerontologist 2012, 52, 460-471.

24. Collins, T. Remembering the past, looking to the future: Christmas as a symbol of change in later life widowhood. Ageing Soc. 2014, 34, 1525-1549.

25. Hill-Collins, P. Black Feminist Thought: Knowledge, Consciousness and the Politics of Empowerment; Routledge: New York, NY, USA, 2000.

26. Crenshaw, K. Mapping the margins: Intersectionality, identity politics, and violence against women of color. Stanf. Law Rev. 1991, 43, 1241-1299.

27. Moore, S. "No matter what I did I would still end up in the same position" age as a factor defining older women's experience of labour market participation. Work Employ. Soc. 2009, 23, 655-671.

28. Calasanti, T. A feminist confronts ageism. J. Aging Stud. 2008, 22, 152-157.

29. Krekula, C. The intersection of age and gender: Reworking gender theory and social gerontology. Curr. Sociol. 2007, 55, 155-171.

30. Freixas, A.; Luque, B.; Reina, A. Critical feminist gerontology: In the back room of research. J. Women Aging 2012, 24, 44-58.

31. Fine, M. Disruptive Voices: The Possibilities of Feminist Research; University of Michigan Press: Ann Arbor, MI, USA, 1992; p. 120.

32. Hooyman, N.; Browne, C.V.; Ray, R.; Richardson, V. Feminist gerontology and the life course. Gerontol. Geriatr. Educ. 2002, 22, 3-26.

33. Netting, F.E. Bridging critical feminist gerontology and social work to interrogate the narrative on civic engagement. Affilia 2011, 26, 239-249.

34. Wild, K.; Wiles, J.L.; Allen, R.E. Resilience: Thoughts on the value of the concept for critical gerontology. Ageing Soc. 2013, 33, 137-158.

35. Robertson, G.K. Transitions in later life: A review of the challenges and opportunities for policy development. Work. Older People 2014, 18, 186-196.

36. Hildon, Z.; Smith, G.; Netuveli, G.; Blane, D. Understanding adversity and resilience at older ages. Sociol. Health Illn. 2008, 30, 726-740.

37. Wong, S.T.; Wu, A.; Gregorich, S.; Pérez-Stable, E.J. What type of social support influences self-reported physical and mental health among older women? J. Aging Health 2014, 26, 663-678.

38. Browne, C.V.; Mokuau, N.; Braun, K.L. Adversity and resiliency in the lives of Native Hawaiian elders. Soc. Work 2009, 54, 253-261. 
39. Marttila, A.; Johansson, E.; Whitehead, M.; Burström, B. Keep going in adversity: Using a resilience perspective to understand the narratives of long-term social assistance recipients in Sweden. Int. J. Equity Health 2013, 12, 1-11.

40. Chapin, R.; Cox, E.O. Changing the paradigm: Strengths-based and empowerment-oriented social work with frail elders. J. Gerontol. Soc. Work 2002, 36, 165-179.

(C) 2015 by the authors; licensee MDPI, Basel, Switzerland. This article is an open access article distributed under the terms and conditions of the Creative Commons Attribution license (http://creativecommons.org/licenses/by/4.0/). 